\title{
Prevalence of sarcopenia in community dwelling outpatient postmenopausal Hungarian women
}

Zoltán Pap ${ }^{1}$, Irina Kalabiska², Ádám Balogh ${ }^{3}$ and Harjit Pal Bhattoa ${ }^{4^{*}}$

\begin{abstract}
Background: Ageing is an inherent feature of life and as per the United Nations, in the year 2020, 985 million women were $\geq 50$ years of age worldwide, and the figure is expected to rise to 1.65 billion by 2050 . Preservation of health and well-being in the elderly are challenging, and on the same note generalized changes in the musculoskeletal system contribute to this scenario. Musculoskeletal changes with ageing are referred to as sarcopenia. Reduced muscle mass and physical performance are hallmarks of sarcopenia, exclaimed with difficulty in independent activity and poor quality of life. Knowing that there is a hiatus in our knowledge as regards to the prevalence of sarcopenia in Hungary, the aim of this study was to determine the prevalence of sarcopenia in a community dwelling outpatient postmenopausal Hungarian cohort using the EWGSOP2 consensus recommendation.
\end{abstract}

Methods: In this cross-sectional study, women arriving for routine bone densitometry examination at the Regional Osteoporosis Center, Department of Obstetrics and Gynecology, Faculty of Medicine, University of Debrecen were invited to participate in the study. A total of a 100 community-dwelling women were recruited who confirmed to the inclusion criteria of self-reported postmenopausal status, $\geq 50$ years of age and gave written informed consent. The study procedures included the self-administered SARC-F questionnaire, followed by assessment of muscle strength, muscle quantity and physical preformance. Muscle strength was determined with the hand grip strength (HGS), appendicular skeletal muscle mass was assessed using dual energy X-ray absorptiometry and physical performance was determined by the gait speed (GS) test.

Results: As per the EWGSOP2 definition, the percentage of study participants with probable sarcopenia (low muscle strength), sarcopenia (low muscle strength and low muscle quantity) and severe sarcopenia (low muscle strength, muscle quantity and low physical performance) was 36, 31 and $8 \%$, respectively. Multiple linear regression analysis revealed that height, weight, HGS and GS were all independent predictors of appendicular skeletal muscle mass.

Conclusion: The 31\% prevalence of sarcopenia in the studied post-menopausal women highlights the need for adequate assessment of the condition in the elderly. Our findings most probably bear public health implications and may accelerate formulation of policies promoting healthy ageing.

Keywords: Sarcopenia, Appendicular skeletal muscle mass, Hand grip strength, Gait speed, Postmenopausal women

*Correspondence: harjit@med.unideb.hu

${ }^{4}$ Department of Laboratory Medicine, Faculty of Medicine, University of Debrecen, Nagyerdei Blvd. 98, Debrecen H-4032, Hungary

Full list of author information is available at the end of the article

\section{Background}

Rosenberg in his paper on the origins of the term sarcopenia cited the Greek words sarx and penia meaning flesh and loss, respectively; and the term reflects an age-related depletion of lean body mass inherently realized as alterations in mobility, nutritional intake and original author(s) and the source, provide a link to the Creative Commons licence, and indicate if changes were made. The images or other third party material in this article are included in the article's Creative Commons licence, unless indicated otherwise in a credit line to the material. If material is not included in the article's Creative Commons licence and your intended use is not permitted by statutory regulation or exceeds the permitted use, you will need to obtain permission directly from the copyright holder. To view a copy of this licence, visit http://creativecommons.org/licenses/by/4.0/. The Creative Commons Public Domain Dedication waiver (http://creativeco mmons.org/publicdomain/zero/1.0/) applies to the data made available in this article, unless otherwise stated in a credit line to the data. 
status, and over-all independence [1]. The definition of sarcopenia has since evolved with a dominant focus on muscle function, defined by muscle strength, muscle power or physical performance, as a potent predictor of relevant clinical outcomes rather than muscle mass alone [2-5]. Preservation of health and well-being in the elderly are challenging, and on the same note generalized changes in the musculoskeletal system contribute to this scenario. Depending on the definition used, the prevalence of sarcopenia ranges between 1 and 53\% [6-42].

Sarcopenia is associated with a multitude of comorbidities having a significant impact on public health $[43,44]$. The consequences of sarcopenia include high mortality, increased risk of falling, prolonged hospitalizations, augmented fracture risk, deprived mobility and physical function, and an inferior quality of life $[6$, 45-50].

As per an estimation by the United Nations, in the year 2020, 985 million women were $\geq 50$ years of age worldwide, and the figure is expected to rise to 1.65 billion by 2050 [51]. As per the Hungarian 2011 consensus, $2,179,606$ women were $\geq 50$ years of age $(21.9 \%$ of the population) [52]. This population may be considered postmenopausal as menopause is universal and shows meager variation in the timing of its onset, i.e., around 50 years of age, across human populations and has remained quite steady over the last 100 years in developed societies [53-55].

Studies suggest that the decline in estrogen levels during menopause may play a role in decline of lean body mass [56, 57]. Furthermore, postmenopausal women with sarcopenia were found to have decreased quality of life in a recent study by Cevei et al. [58].

In the past, diagnosis of sarcopenia was perhaps hindered by lack of a broadly accepted clinical definition. The European Working Group on Sarcopenia in Older People (EWGSOP) coined a definition that provided a framework for the diagnosis of sarcopenia in 2010 [59]. The definition was refined in 2019, and includes assessment of muscle strength, muscle mass and physical performance within a well-defined algorithm [60]. Although the EWGSOP2 consensus provides an exhaustive list of methodologies, they suggest hand grip strength determination for assessing muscle strength, dual-energy X-ray absorptiometry (DXA) to determine muscle quantity and gait speed to determine physical performance [60].

Knowing that there is a hiatus in our knowledge as regards to the prevalence of sarcopenia in Hungary, the aim of this study was to determine the prevalence of sarcopenia in a postmenopausal Hungarian cohort using the EWGSOP2 consensus recommendation.

\section{Methods}

\section{Patients}

In this cross-sectional study, women arriving for routine bone densitometry examination at the Regional Osteoporosis Center, Department of Obstetrics and Gynecology, Faculty of Medicine, University of Debrecen were invited to participate in the study. A total of a 100 communitydwelling women were recruited who confirmed to the inclusion criteria of self-reported postmenopausal status, $\geq 50$ years of age and gave written informed consent. Self-reported menopause was defined as amenorrhea of at least 12 consecutive months after the last menstrual period [61]. Upon arrival to the out-patient department, patients were verbally informed about the study initiative with a brief summary on the importance of sarcopenia and a detailed description about the various study procedures. The study target of a 100 recruits was met in 3 months between January and March of 2019. None of the women declined invitation to participate in the study. The study was performed according to the Declaration of Helsinki and approved by the Ethics Committee of the University of Debrecen, Hungary (approval No. 5314-2019).

\section{Study procedures}

The study commenced with the self-administered 5-item strength, assistance walking, rise from a chair, climb stairs and falls (SARC-F) questionnaire, followed by assessment of muscle strength, muscle quantity and physical preformance.

\section{SARC-F questionnaire}

The SARC-F questionnaire is recommended by the EWGSOP2 as means of case-finding, where self-reports on signs that are characteristic of sarcopenia are noted from the patient [60]. The 5-item SARC-F questionnaire is a screening tool for risk of sarcopenia, where the patients insight of their extent in strength, walking ability, rising from a chair, stair climbing and acquaintances with falls is registered. As described by Malmstrom et al., the maximum SARC-F scale score is 10 (with $0-2$ points for each of the 5 component; where a score of 0 is the best and 10 the worst) and a score of $\geq 4$ is an indication for a diagnostic work-up to assess sarcopenia [62]. Strength is perceived by asking respondents how much difficulty they have lifting or carrying roughly $4.5 \mathrm{kgs}$ i.e., $10 \mathrm{lbs}$. $(0=$ no difficulty, $1=$ some, and $2=a$ lot or unable to do $)$. Assistance walking is assessed by noting the amount of difficulty the participant has when walking across a room and need for help or aids to do this $(0=$ no difficulty, $1=$ some difficulty, and $2=$ a lot of difficulty, use aids, or need of personal help). Rise from a chair pertains to the amount of difficulty in transferring from a chair or bed 
and whether they need help or aids to do this $(0=$ no difficulty, $1=$ some difficulty, and $2=$ a lot of difficulty, use aids, or need of help). Climb stairs is determined by querying the amount of difficultly the respondent has in climbing a flight of 10 steps $(0=$ no difficulty, $1=$ some, and $2=$ a lot or unable to do). For falls, reporting falling four times or more in the previous year is scored as 2 , 1-3 times a year as 1 , and for no reported falls as 0 .

\section{Assessment of muscle strength}

Muscle strength was determined with the hand grip strength (HGS) that was measured using the Jamar technologies hydraulic hand dynamometer (JLW Instruments, Chicago, IL, USA / Sammons Preston Rolyan, Bolingbrook, IL) as described by Roberts et al. [63]. In short, the patient is made comfortable in a chair with fixed legs and arms and a back support, with their forearms on the chair arms and their wrist, with their thumb facing upwards, over the end of the arms of the chair. The use of the dynamometer is demonstrated, and the importance of registering the best score upon tight gripping is emphasized. With the instrument comfortably in the patients' right hand, the thumb is positioned around one side of the handle and the fingers around the other. In order to counteract the effect of gravity, the examiner rests the base of the instrument with his or her palm ensuring that its movement is not restricted. A strong squeeze is encouraged until the measuring needle stops rising. The grip strength is read from the outside dial in kilograms. The measurement is repeated for the left hand, with two additional measurements for each hand and the highest of the six readings and hand dominance is recorded.

\section{Assessment of the muscle mass}

Dual-energy X-ray absorptiometry whole body scan was performed with the LUNAR Prodigy (GE-Lunar Corp., Madison, WI, USA) densitometer by a trained and certified DXA technician to assess the fat mass, lean mass, and bone mass of various regions of interest. Appendicular skeletal muscle mass (ASM) was calculated as the sum of lean mass in the arms and legs (all four extremities), assuming that all non-fat and non-bone tissue is skeletal muscle [64]. Since the EWGSOP2 criteria makes no recommendation for adjustment of body size, ASM $(<15 \mathrm{~kg})$ per se was used to define sarcopenia [60].

\section{Assessment of physical performance}

Physical performance was assessed using the $4 \mathrm{~m}$ usual walking speed test also known as the gait speed (GS) test $[65,66]$. Patients covered $4 \mathrm{~m}$ on a straight clearly marked course in their usual pace, with a cane or walker if normally used, and the time taken was measured using a stopwatch. Speed was the distance travelled divided by the time taken measured by a stop watch.

As suggested by the EWGSOP2 consensus, the cutoff values for the measured variables are summarized in Table 1 [60].

As per the 2018 operational definition of sarcopenia, patients with low muscle strength are identified as those with probable sarcopenia, diagnosis of sarcopenia is considered confirmed by additional documentation of low muscle quantity or quality, additionally sarcopenia is considered severe when the patient presents with low muscle strength, muscle quantity or quality and low physical performance [60].

\section{Statistical methods}

Descriptive statistics for all continuous variables are presented as median and range. The normality of distribution was assessed using the Kolmogorov-Smirnov test. The Spearman's correlation coefficient was calculated for correlation analysis. Univariate and multiple regression analysis using the stepwise method was used to determine correlations and independent associations between parameters. Appendicular skeletal muscle mass was the dependent variables and SARC-F, weight, height, body mass index, HGS and GS were independent variables. The $\beta$ standardized linear coefficients showing linear correlations between two parameters were determined. Independent association between the dependent and independent variables was indicated by the B $(95 \% \mathrm{CI})$ regression coefficient. Statistical significance was defined as $p$ values $<0.05$. All analyses were performed using the SPSS Statistics software, version 25.0 (IBM Corps., Armonk, NY, USA).

\section{Results}

The characteristics of the patients in this cross-sectional study are shown in Table 2. As per the EWGSOP2 definition, the percentage of study participants with probable sarcopenia (low muscle strength), sarcopenia (low muscle strength and low muscle quantity) and severe sarcopenia (low muscle strength, muscle quantity and low physical performance) was 36,31 and $8 \%$, respectively (Fig. 1). On

Table 1 Indicator cut-off values for the studied parameters

\begin{tabular}{ll}
\hline Parameter & Cut-off values \\
\hline Strength, assistance walking, rise from a chair, climb & $\geq 4$ \\
stairs and falls (SARC-F) questionnaire & \\
Hand Grip Strength & $<16 \mathrm{~kg}$ \\
Appendicular skeletal muscle mass (ASM) & $<15 \mathrm{~kg}$ \\
$4-\mathrm{m}$ gait speed & $\leq 0.8 \mathrm{~m} / \mathrm{s}$ \\
\hline
\end{tabular}


Table 2 Patient Characteristics

\begin{tabular}{|c|c|c|c|}
\hline Parameters (median, range) & $\begin{array}{l}\text { All participants } \\
(n=100)\end{array}$ & $\begin{array}{l}\text { ASM }<15 \mathrm{~kg} \\
(n=31)\end{array}$ & $\begin{array}{l}\text { ASM } \geq 15 \mathrm{~kg} \\
(n=69)\end{array}$ \\
\hline Age (years) & $66(50-84)$ & $67(50-83)$ & $66(50-84)$ \\
\hline Weight (kg) & $64.5(41-95)$ & $57(41-71)^{\mathrm{a}}$ & $68(47-95)^{\mathrm{a}}$ \\
\hline Height $(\mathrm{cm})$ & $157(141-170)$ & $152.5(141-170)^{b}$ & $158(146-169)^{b}$ \\
\hline Body mass index $\left(\mathrm{kg} / \mathrm{m}^{2}\right)$ & $26.2(18.8-36.5)$ & $24.2(19.2-31.3)^{c}$ & $27.5(18.8-36.5)^{c}$ \\
\hline SARC-F questionnaire score & $3(0-9)$ & $6(4-9)^{d}$ & $2(0-7)^{d}$ \\
\hline Hand grip strength (kg) & $20.6(10.9-27.9)$ & $12.8(10.9-14.5)^{\mathrm{e}}$ & $21.2(11.1-27.9)^{\mathrm{e}}$ \\
\hline Gait Speed (m/s) & $1.11(0.39-1.61)$ & $1.05(0.39-1.61)^{f}$ & $1.11(0.9-1.61)^{f}$ \\
\hline Left upper extremity lean mass (kg) & $2.17(1.29-3.09)$ & $1.88(1.29-2.28)^{\mathrm{g}}$ & $2.30(1.69-3.09)^{9}$ \\
\hline Left lower extremity lean mass $(\mathrm{kg})$ & $5.65(3.50-9.33)$ & $4.84(3.50-5.44)^{h}$ & $5.97(5.29-9.33)^{h}$ \\
\hline Right upper extremity lean mass (kg) & $2.22(1.49-3.17)$ & $1.94(1.55-2.30)^{i}$ & $2.36(1.49-3.17)^{i}$ \\
\hline Right lower extremity lean mass (kg) & $5.71(3.70-9.54)$ & $5.02(3.70-5.61)^{j}$ & $6.01(5.27-9.54)^{j}$ \\
\hline ASM (kg) & $15.79(10.81-24.10)$ & $13.82(10.81-14.88)^{\mathrm{k}}$ & $16.41(15.00-24.10)^{k}$ \\
\hline Body mass index adjusted ASM & $0.610(0.378-1.097)$ & $0.577(0.378-0.744)^{\prime}$ & $0.626(0.435-1.097)^{1}$ \\
\hline
\end{tabular}

$\mathrm{a}, \mathrm{b}, \mathrm{c}, \mathrm{d}, \mathrm{f}, \mathrm{g}, \mathrm{h}, \mathrm{i}, \mathrm{j}, \mathrm{kl}, \mathrm{p} p<0.001$. ASM: Appendicular skeletal muscle mass. SARC-F: 5 -item strength, assistance walking, rise from a chair, climb stairs and falls (SARC-F) questionnaire

comparing study participants with low $(<15 \mathrm{~kg})$ and normal ( $\geq 15 \mathrm{~kg}$ ) ASM, significant differences were found in weight (57 (41-71) kg versus $67.5(47-95) \mathrm{kg} ; p<0.001)$, height (152.5 (141-170) cm versus $158(146-169) \mathrm{cm}$; $p<0.001)$, body mass index $\left(24.2(19.2-31.3) \mathrm{kg} / \mathrm{m}^{2}\right.$ versus $\left.\left.27.5(18.8-36.5) \mathrm{kg} / \mathrm{m}^{2}\right) ; p<0.001\right)$, SARC-F questionnaire score $(6(4-9)$ versus $2(0-7) ; p<0.001)$, hand grip strength (12.6 (10.9-14.5) kg versus 21.2 (11.1-27.9) kg; $p<0.001)$ and gait Speed $(1.05(0.39-1.61) \mathrm{m} / \mathrm{s}$ versus $1.11(0.9-1.61) \mathrm{m} / \mathrm{s} ; p<0.001)$. All parameters used in the calculation of ASM, i.e., left upper extremity lean mass, left lower extremity lean mass, right upper extremity lean mass and right lower extremity lean mass, were all statistically significantly lower in those with ASM $<15 \mathrm{~kg}$. BMI adjusted ASM as suggested by Cawthon et al. was significantly lower in those with ASM < $15 \mathrm{~kg}$ [67].

Appendicular skeletal muscle mass showed statistically significant correlation with height, weight, body mass index, SARC-F questionnaire score, HGS and GS (Table 3).

Upon univariate analysis of the cohort data, participants with lower appendicular skeletal muscle mass had lower height, weight, body mass index, HGS and GS, and higher SARC-F score (Table 4).

Multiple linear regression analysis revealed that height, weight, HGS and GS were independent predictors of appendicular skeletal muscle mass (Table 5).

\section{Discussion}

Using the algorithm detailed by the EWGSOP2, diagnostic work-up for sarcopenia was dictated in 40 (40\%) study participants using the SARC-F questionnaire score, sarcopenia was probable in 36 of these individuals as per the muscle strength findings, sarcopenia was confirmed in 31 based on their muscle mass and 8 of them were diagnosed as having severe sarcopenia following assessment of their physical performance. Although the EWGSOP2 criteria do not explicitly define presarcopenia, those with a SARC-F score of $\geq 4$ and ASM $<15 \mathrm{~kg}$ may well be categorized as presarcopenic, and are candidates for stringent follow-up in the near future. In our study, 5 individuals confirmed to the criteria of presarcopenia (Fig. 1).

The prevalence of sarcopenia has been reported by quite a few from various parts of the globe [6-58]. Table 6 lists the studies conducted in the past two decades. Table 6 summarizes the characteristics of the studied cohorts, the various techniques employed to assess muscle mass, muscle strength and physical performance, and the prevalence of sarcopenia for both sexes where available. Although the 2010 EWGSOP consensus delineates a frame-work for the assessment of sarcopenia, it is lenient in allowing the variables to be measured by various techniques that inherently leaves room for disparities as regards to comparison of published prevalence data [59]. The published data reports a prevalence of sarcopenia ranging between 1 and 53\%, the aforementioned may offer explanation for this wide range, but other factors such as the variable age of the study participants and inclusion or non-inclusion of both sexes in the study cohort may also be contributory. It needs mention that apart from the EWGSOP consensus recommendations, the International working group on sarcopenia (IWG) and the Asian working group for sarcopenia (AWGS) 


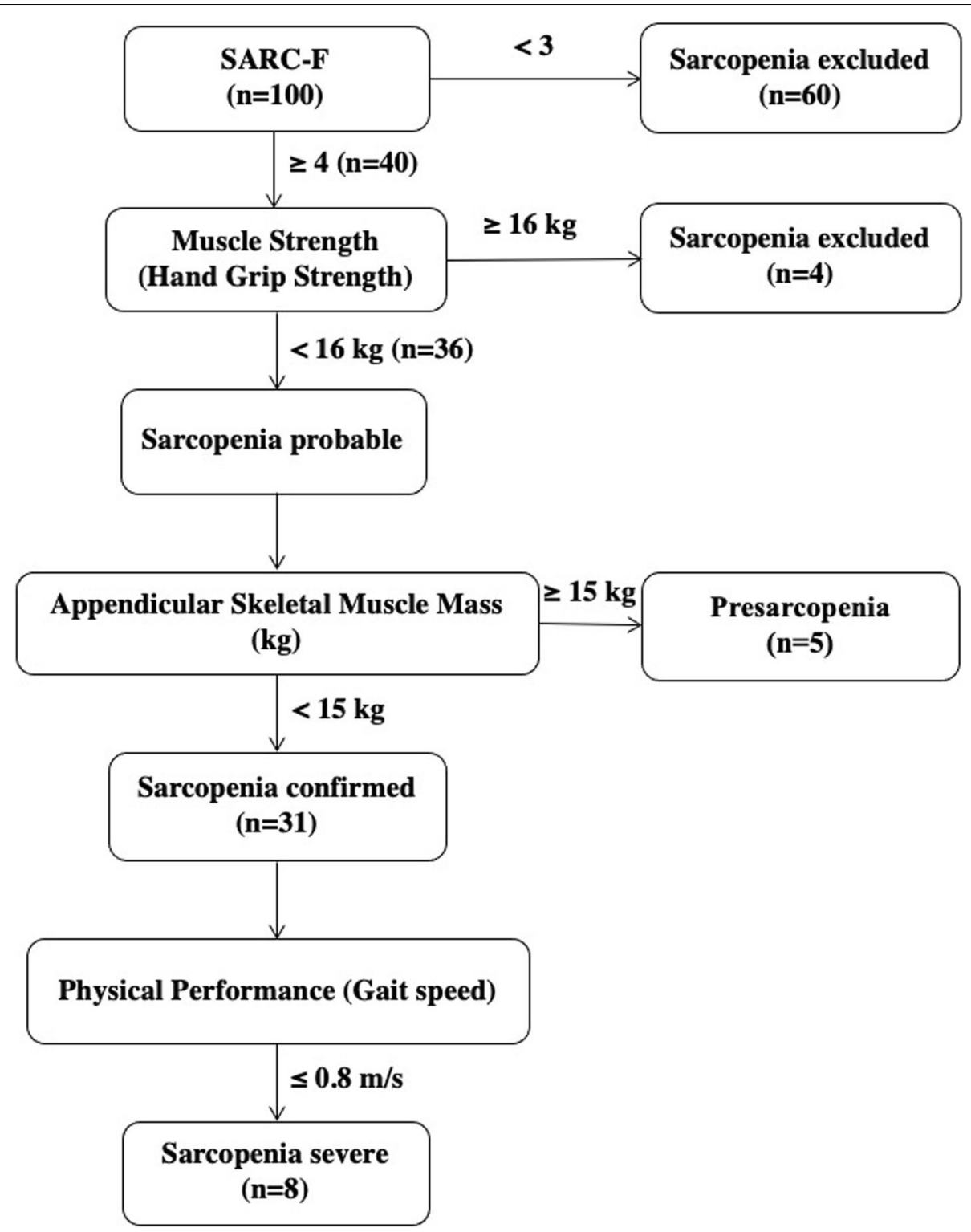

Fig. 1 EWGSOP2 consensus recommended algorithm for sarcopenia case finding in the studied cohort

Table 3 Correlation analysis between appendicular skeletal muscle mass and the dependent variables

\begin{tabular}{|c|c|c|c|c|c|c|c|}
\hline & & Height & Weight & BMI & SARC-F & HGS & GS \\
\hline ASM & $\begin{array}{l}\text { Spearman's } \rho \\
p \text { value }\end{array}$ & $\begin{array}{l}0.516 \\
<0.001\end{array}$ & $\begin{array}{l}0.602 \\
<0.001\end{array}$ & $\begin{array}{l}0.389 \\
<0.001\end{array}$ & $\begin{array}{l}-0.612 \\
<0.001\end{array}$ & $\begin{array}{l}0.628 \\
<0.001\end{array}$ & $\begin{array}{l}0.347 \\
<0.001\end{array}$ \\
\hline
\end{tabular}

ASM Appendicular skeletal muscle mass, BMI Body mass index, SARC-F 5-item strength, assistance walking, rise from a chair, climb stairs and falls (SARC-F) questionnaire, HGS Hand grip strength, GS Gait speed

recommendations are also in use [59, 68, 69]. The use of the International working group on sarcopenia criteria by Tramontano et al may not allow head-to-head comparison of the reported prevalence of sarcopenia in Peru to the other studies listed in Table 6. Furthermore, the Asian working group for sarcopenia recommendations have been used in quite a few Asian studies [40-42]. 
Table 4 Results of the univariate analyses

\begin{tabular}{|c|c|c|c|c|}
\hline \multirow[t]{2}{*}{ Dependent variable } & \multirow[t]{2}{*}{ Independent variable } & \multicolumn{3}{|l|}{ Univariate analysis } \\
\hline & & $B(95 \% \mathrm{Cl})$ & $\beta$ & $p$ value \\
\hline \multirow[t]{6}{*}{ Appendicular Skeletal Muscle Mass } & Height & $0.201(0.143-0.259)$ & 0.570 & $<0.001$ \\
\hline & Weight & $0.121(0.086-0.155)$ & 0.575 & $<0.001$ \\
\hline & Body Mass Index & $0.193(0.083-0.303)$ & 0.332 & 0.001 \\
\hline & SARC-F & $-0.587(-0.742--0.432)$ & -0.605 & $<0.001$ \\
\hline & Hand Grip Strength & $0.253(0.187-0.319)$ & 0.611 & $<0.001$ \\
\hline & Gait Speed & $3.390(1.676-5.103)$ & 0.369 & $<0.001$ \\
\hline
\end{tabular}

SARC-F 5-item strength, assistance walking, rise from a chair, climb stairs and falls (SARC-F) questionnaire

Table 5 Multiple regression analysis of Appendicular Skeletal Muscle Mass

\begin{tabular}{lllll}
\hline Dependent variable & Independent variable & Multivariate analysis & \\
\cline { 3 - 4 } & & $\boldsymbol{B ( 9 5 \% \mathrm { Cl } )}$ & $\boldsymbol{\beta}$ & $\boldsymbol{p}$ value \\
\hline Appendicular Skeletal Muscle Mass & Height & $0.125(0.073-0.176)$ & 0.354 & $<0.001$ \\
& Weight & $0.046(0.014-0.078)$ & 0.219 & 0.006 \\
& Hand Grip Strength & $0.147(0.087-0.207)$ & 0.354 & 0.189 \\
\hline
\end{tabular}

The probable limitations of our study are the relatively low number of participants, and the non-inclusion of men. The participants in this study were women who were referred for a routine bone densitometry examination and per se do not represent the general population. There may perhaps be a selection bias, since postmenopausal women reluctant to have routine checkups may have been missed from the study, moreover there may have been a greater likelihood of inclusion of those with musculoskeletal complaints. The reliability of self-reported menopausal status may be confounded by the subjective recollection of the reporter and perhaps complimentary assessment of folliculus stimulating hormone levels could have furthered more precise documentation of the the menopausal status of the studied women $[70,71]$. The sample size of the studied population was limited to a 100 participants. The main aim of the present study was to estimate the prevalence of sarcopenia in a community dwelling postmenopausal out-patient population. For sample size calculation the expected proportion or prevalence in the population based to previous studies or pilot studies is a prerequisite [72]. There is no Hungarian data on the prevalence of sarcopenia, and knowing from other populations that previous estimates of prevalence of sarcopenia in women, from various age groups, range from $0.9-43.1 \%$ albeit based on different definitions of sarcopenia (Table 6), the sample size chosen in the present study would suffice to an estimated prevalence of below $7 \%$.
The finding of the present study at best qualify as findings from a pilot study given its inherent limitations and dictates validation on a sample size nurtured from the general population pool. Additional limitations include, lack of data on potential confounders such as total body fat, physical activity, diet and race.

Most studies report no significant association between sarcopenia prevalence and gender $[8,12,14,73,74]$. Nonetheless, Landi et al. reported that men were more commonly affected as compared to women [6] and Patel et al. in their study showed a higher prevalence of sarcopenia in women than in men [75]. This lack of consensus and the reported disparity among studies on the prevalence of sarcopenia in men and women advocate further investigations on the effect of gender on the prevalence of sarcopenia.

Estrogen decline, especially following menopause is one the factors implicated in the loss of lean muscle mass in women [76].

In our study, we used the EWGSOP2 recommendations published in 2019 [60]. As compared to the EWGSOP, the EWGSOP2 has better delineated the techniques recommended to assess muscle strength, muscle mass and physical performance $[59,60]$. We used the DXA technique to assess muscle strength using the appendicular skeletal muscle mass. As recommended by the EWGSOP2 criteria, ASM in our cohort was not adjusted for body size [60]. Nonetheless, the use of unadjusted ASM to diagnose sarcopenia limits its comparability to 


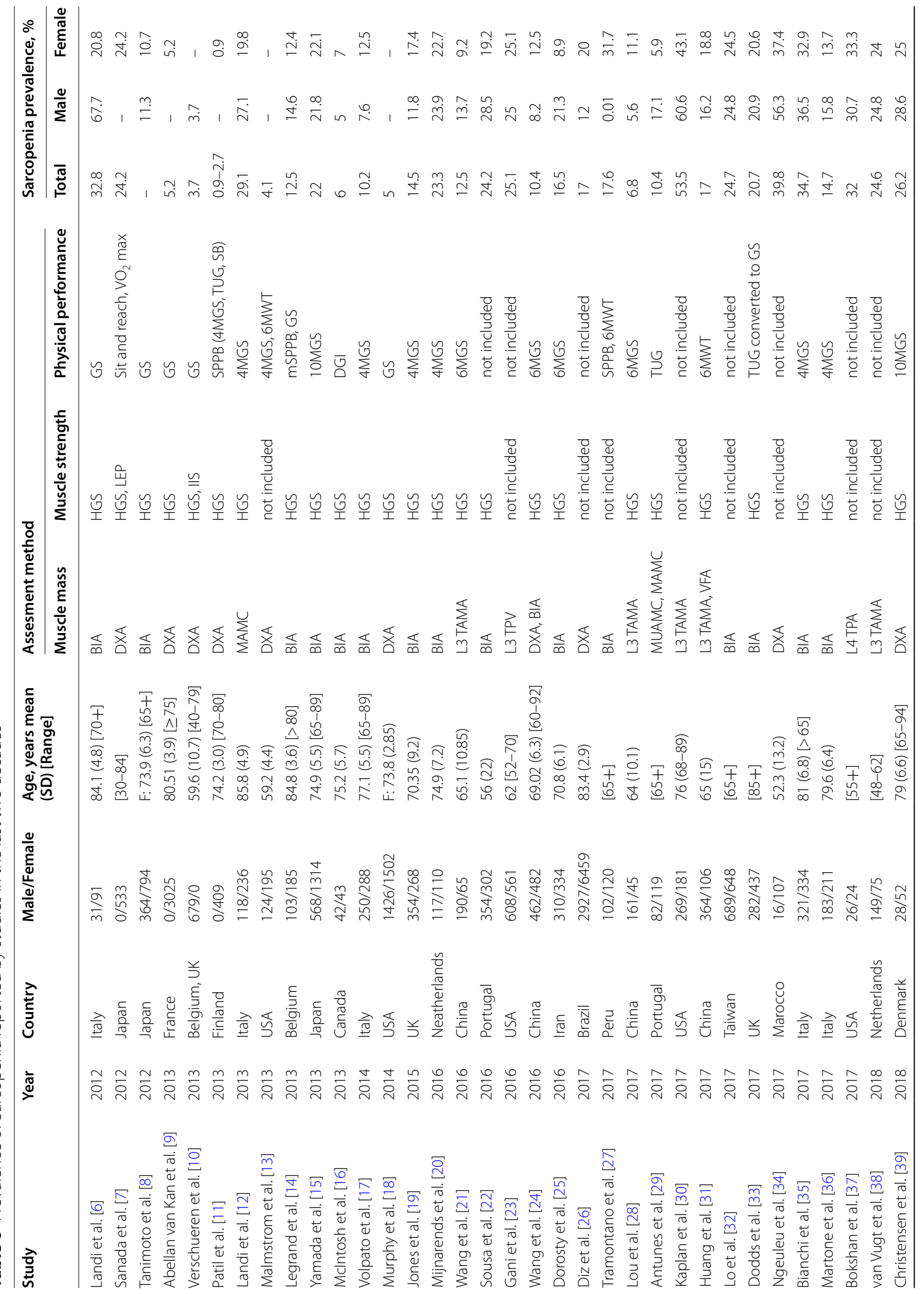




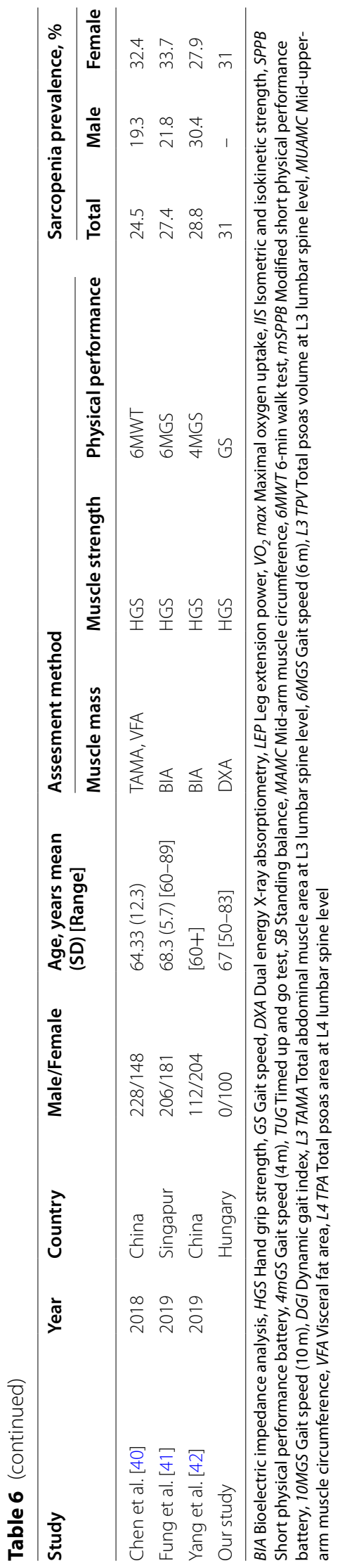


previous studies where ASM was adjustment for height or body mass index.

Our findings most probably bear public health implications and may accelerate formulation of policies promoting healthy ageing.

\section{Conclusion}

The $31 \%$ prevalence of sarcopenia in the studied postmenopausal women highlights the need for adequate assessment of the condition in the elderly.

\begin{abstract}
Abbreviations
10MGS: Gait Speed (10 m); 4MGS: Gait Speed (4 m); 6MGS: Gait Speed (6 Meters); 6MWT: 6-Minutes Walk Test; 95\%Cl: 95 Percentage Confidence Interval; ASM: Appendicular Skeletal Muscle Mass; AWGS: Asian Working Group for Sarcopenia; BIA: Bioelectric Impedance Analysis; BMI: Body Mass Index; DGI: Dynamic Gait Index; DXA: Dual Energy X-Ray Absorptiometry; EWGSOP: European Working Group on Sarcopenia in Older People; EWGSOP2: European Working Group on Sarcopenia in Older People consensus of 2019; GS: Gait Speed; HGS: Hand Grip Strength; IIS: Isometric and Isokinetic Strength; IWG: International Working Group on Sarcopenia; L3 TAMA: Total Abdominal Muscle Area at L3 Lumbar Spine Level; L3 TPV: Total Psoas Volume at L3 Lumbar Spine Level; L4 TPA: Total Psoas Area at L4 Lumbar Spine Level; LEP: Leg Extension Power; MAMC: Mid-Arm Muscle Circumference; mSPPB: Modified Short Physical Performance Battery; MUAMC: Mid-Upper-Arm Muscle Circumference; SARC-F: 5-Item Strength, Assistance Walking, Rise from a Chair, Climb Stairs and Falls Questionnaire; SB: Standing Balance; SPPB: Short Physical Performance Battery; TUG: Timed Up and Go Test; VFA: Visceral Fat Area; $\mathrm{VO}_{2}$ max: Maximal Oxygen Uptake; WHO: World Health Organization.
\end{abstract}

\section{Supplementary Information}

The online version contains supplementary material available at https://doi. org/10.1186/s12891-022-05167-2.

\section{Additional file 1.}

\section{Acknowledgements}

Not applicable.

\section{Authors' contributions}

Z.P. recruited patients, coordinated and performed patient examinations, collected and interpreted data and contributed in writing the manuscript. I.K. conceived the study design, interpreted data and contributed in writing the manuscript and its critical evaluation. A.B. recruited patients, coordinated and performed patient examinations, and contributed in writing the manuscript. H.P.B. conceived the study design, interpreted data and was a major contributor in writing the manuscript and its critical evaluation. The author(s) read and approved the final manuscript.

\section{Funding}

Open access funding provided by University of Debrecen.

\section{Availability of data and materials}

All data generated or analyzed during this study are included in this published article and its supplementary information file.

\section{Declarations}

\section{Ethics approval and consent to participate}

All study participants gave written informed consent. The study was performed according to the Declaration of Helsinki and approved by the Regional Ethics Committee of the University of Debrecen, Hungary (approval No. DE RKEB/IKEB 5314-2019).
Consent for publication

Not applicable.

\section{Competing interests}

The authors declare that they have no competing interests.

\section{Author details}

${ }^{1}$ Kalman Laki Doctoral School of the University of Debrecen, Department of Traumatology and Hand Surgery, Faculty of Medicine, University of Debrecen, Debrecen, Hungary. ${ }^{2}$ University of Physical Education, Research Center for Sport Physiology, Budapest, Hungary. ${ }^{3}$ Regional Osteoporosis Center, Department of Obstetrics and Gynecology, Faculty of Medicine, University of Debrecen, Debrecen, Hungary. ${ }^{4}$ Department of Laboratory Medicine, Faculty of Medicine, University of Debrecen, Nagyerdei Blvd. 98, Debrecen $\mathrm{H}-4032$, Hungary.

Received: 23 December 2021 Accepted: 25 February 2022

Published online: 04 March 2022

\section{References}

1. Rosenberg $\mid \mathrm{H}$. Sarcopenia: origins and clinical relevance. J Nutr. 1997;127(5 Suppl):990S-1S.

2. Cruz-Jentoft AJ, Sayer AA. Sarcopenia. Lancet. 2019 Jun 29;393(10191):2636-2646. Clark BC, Manini TM. Sarcopenia =/=dynapenia. J Gerontol A Biol Sci Med Sci. 2008;63(8):829-34.

3. Goodpaster BH, Park SW, Harris TB, Kritchevsky SB, Nevitt M, Schwartz $A V$, et al. The loss of skeletal muscle strength, mass, and quality in older adults: the health, aging and body composition study. J Gerontol A Biol Sci Med Sci. 2006;61(10):1059-64

4. Delmonico MJ, Harris TB, Visser M, Park SW, Conroy MB, Velasquez-Mieyer $P$, et al. Health, aging, and body. Longitudinal study of muscle strength, quality, and adipose tissue infiltration. Am J Clin Nutr. 2009;90(6):1579-85.

5. Visser M, Schaap LA. Consequences of sarcopenia. Clin Geriatr Med. 2011;27(3):387-99.

6. Landi F, Liperoti R, Fusco D, Mastropaolo S, Quattrociocchi D, Proia A, et al. Sarcopenia and mortality among older nursing home residents. J Am Med Dir Assoc. 2012;13(2):121-6.

7. Sanada K, lemitsu M, Murakami H, Gando Y, Kawano H, Kawakami R, et al. Adverse effects of coexistence of sarcopenia and metabolic syndrome in Japanese women. Eur J Clin Nutr. 2012;66(10):1093-8.

8. Tanimoto Y, Watanabe M, Sun W, Sugiura Y, Tsuda Y, Kimura M, et al. Association between sarcopenia and higher-level functional capacity in daily living in community-dwelling elderly subjects in Japan. Arch Gerontol Geriatr. 2012;55(2):e9-13.

9. Abellan Van Kan G, Cesari M, Gillette-Guyonnet S, Dupuy C, Nourhashémi F, Schott A, et al. Sarcopenia and cognitive impairment in elderly women: results from the EPIDOS cohort. Age Ageing. 2013;42:196-202.

10. Verschueren S, Gielen E, O'Neill TW, Pye SR, Adams JE, Ward KA, et al. Sarcopenia and its relationship with bone mineral density in middle-aged and elderly European men. Osteoporos Int. 2013;24(1):87-98.

11. Patil R, Uusi-Rasi K, Pasanen M, Kannus P, Karinkanta S, Sievänen H. Sarcopenia and osteopenia among 70-80-year-old home-dwelling Finnish women: prevalence and association with functional performance. Osteoporos Int. 2013;24(3):787-96.

12. Landi F, Liperoti R, Russo A, Giovannini S, Tosato M, Barillaro C, et al. Association of anorexia with sarcopenia in a community-dwelling elderly population: results from the ilSIRENTE study. Eur J Nutr. 2013;52(3):1261-8.

13. Malmstrom TK, Miller DK, Herning MM, Morley JE. Low appendicular skeletal muscle mass (ASM) with limited mobility and poor health outcomes in middle-aged African Americans. J Cachexia Sarcopenia Muscle. 2013;4(3):179-86.

14. Legrand D, Vaes B, Matheï C, Swine C, Degryse J-M. The prevalence of sarcopenia in very old individuals according to the European consensus definition: insights from the BELFRAIL study. Age Ageing. 2013;42(6):727-34.

15. Yamada M, Nishiguchi S, Fukutani N, Tanigawa T, Yukutake T, Kayama H, et al. Prevalence of sarcopenia in community-dwelling Japanese older adults. J Am Med Dir Assoc. 2013;14(12):911-5. 
16. Mclntosh El, Smale KB, Vallis LA. Predicting fat-free mass index and sarcopenia: a pilot study in community-dwelling older adults. Age (Dordr). 2013;35(6):2423-34.

17. Volpato S, Bianchi L, Cherubini A, Landi F, Maggio M, Savino E, et al. Prevalence and clinical correlates of sarcopenia in community-dwelling older people: application of the EWGSOP definition and diagnostic algorithm. J Gerontol A Biol Sci Med Sci. 2014;69(4):438-46.

18. Murphy RA, Ip EH, Zhang Q, Boudreau RM, Cawthon PM, Newman $A B$, et al. Transition to sarcopenia and determinants of transitions in older adults: a population-based study. J Gerontol A Biol Sci Med Sci. 2014;69(6):751-8.

19. Jones SE, Maddocks M, Kon SSC, Canavan JL, Nolan CM, Clark AL, et al. Sarcopenia in COPD: prevalence, clinical correlates and response to pulmonary rehabilitation. Thorax. 2015;70(3):213-8.

20. Mijnarends DM, Schols JMGA, Halfens RJG, Meijers JMM, Luiking YC, Verlaan S, et al. Burden-of-illness of Dutch community-dwelling older adults with sarcopenia: health related outcomes and costs. Eur Geriatr Med. 2016;7:276-84

21. Wang SL, Zhuang CL, Huang DD, Pang WY, Lou N, Chen FF, et al. Sarcopenia adversely impacts postoperative clinical outcomes following gastrectomy in patients with gastric Cancer: a prospective study. Ann Surg Oncol. 2016;23(2):556-64.

22. Sousa AS, Guerra RS, Fonseca I, Pichel F, Ferreira S, Amaral TF. Financial impact of sarcopenia on hospitalization costs. Eur J Clin Nutr. 2016;70(9):1046-51.

23. Gani F, Buettner S, Margonis GA, Sasaki K, Wagner D, Kim Y, et al. Sarcopenia predicts costs among patients undergoing major abdominal operations. Surgery. 2016;160(5):1162-71.

24. Wang H, Hai S, Cao L, Zhou J, Liu P, Dong BR. Estimation of prevalence of sarcopenia by using a new bioelectrical impedance analysis in Chinese community-dwelling elderly people. BMC Geriatr. 2016;16(1):216.

25. Dorosty A, Arero G, Chamar M, Tavakoli S. Prevalence of sarcopenia and its association with socioeconomic status among the elderly in Tehran. Ethiop J Health Sci. 2016;26:389-96.

26. Diz JBM, Leopoldino AAO, Moreira BS, Henschke N, Dias RC, Pereira LSM, et al. Prevalence of sarcopenia in older Brazilians: a systematic review and meta-analysis. Geriatr Gerontol Int. 2017;17(1):5-16.

27. Tramontano A, Veronese N, Sergi G, Manzato E, Rodriguez-Hurtado $D$, Maggi S, et al. Prevalence of sarcopenia and associated factors in the healthy older adults of the Peruvian Andes. Arch Gerontol Geriatr. 2017;68:49-54.

28. Lou N, Chi CH, Chen XD, Zhou CJ, Wang SL, Zhuang CL, et al. Sarcopenia in overweight and obese patients is a predictive factor for postoperative complication in gastric cancer: a prospective study. Eur J Surg Oncol. 2017;43(1):188-95.

29. Antunes AC, Araújo DA, Veríssimo MT, Amaral TF. Sarcopenia and hospitalisation costs in older adults: a cross-sectional study. Nutr Diet. 2017;74:46-50.

30. Kaplan SJ, Pham TN, Arbabi S, Gross JA, Damodarasamy M, Bentov I, et al. Association of Radiologic Indicators of frailty with 1-year mortality in older trauma patients: opportunistic screening for sarcopenia and osteopenia. JAMA Surg. 2017;152(2):e164604.

31. Huang DD, Zhou CJ, Wang SL, Mao ST, Zhou XY, Lou N, et al. Impact of different sarcopenia stages on the postoperative outcomes after radical gastrectomy for gastric cancer. Surgery. 2017;161(3):680-93.

32. Lo YC, Wahlqvist ML, Huang YC, Chuang SY, Wang CF, Lee MS. Medical costs of a low skeletal muscle mass are modulated by dietary diversity and physical activity in community-dwelling older Taiwanese: a longitudinal study. Int J Behav Nutr Phys Act. 2017;14(1):31.

33. Dodds RM, Granic A, Davies K, Kirkwood TB, Jagger C, Sayer AA. Prevalence and incidence of sarcopenia in the very old: findings from the Newcastle 85+ study. J Cachexia Sarcopenia Muscle. 2017;8(2):229-37.

34. Ngeuleu A, Allali F, Medrare L, Madhi A, Rkain H, Hajjaj-Hassouni N. Sarcopenia in rheumatoid arthritis: prevalence, influence of disease activity and associated factors. Rheumatol Int. 2017;37(6):1015-20.

35. Bianchi L, Abete P, Bellelli G, Bo M, Cherubini A, Corica F, et al. Prevalence and clinical correlates of sarcopenia, identified according to the EWGSOP definition and diagnostic algorithm, in hospitalized older people: the GLISTEN study. J Gerontol A Biol Sci Med Sci. 2017;72(11):1575-81.
36. Martone AM, Bianchi L, Abete P, Bellelli G, Bo M, Cherubini A, et al. The incidence of sarcopenia among hospitalized older patients: results from the Glisten study. J Cachexia Sarcopenia Muscle. 2017;8(6):907-14.

37. Bokshan SL, Han A, DePasse JM, Marcaccio SE, Eltorai AEM, Daniels AH. Inpatient costs and blood transfusion rates of sarcopenic patients following thoracolumbar spine surgery. J Neurosurg Spine. 2017;27(6):676-80.

38. Van Vugt JLA, Buettner S, Alferink LJM, Bossche N, de Bruin RWF, Darwish Murad S, et al. Low skeletal muscle mass is associated with increased hospital costs in patients with cirrhosis listed for liver transplantation-a retrospective study. Transpl Int. 2018;31(2):165-74.

39. Christensen MG, Piper KS, Dreier R, Suetta C, Andersen HE. Prevalence of sarcopenia in a Danish geriatric out-patient population. Dan Med J. 2018;65(6):A5485.

40. Chen WZ, Chen XD, Ma LL, Zhang FM, Lin J, Zhuang CL, et al. Impact of visceral obesity and sarcopenia on short-term outcomes after colorectal Cancer surgery. Dig Dis Sci. 2018;63(6):1620-30.

41. Fung FY, Koh YLE, Malhotra R, Ostbye T, Lee PY, Shariff Ghazali S, et al. Prevalence of and factors associated with sarcopenia among multi-ethnic ambulatory older Asians with type 2 diabetes mellitus in a primary care setting. BMC Geriatr. 2019;19(1):122.

42. Yang LJ, Wu GH, Yang YL, Wu YH, Zhang L, Wang MH, et al. Nutrition, physical exercise, and the prevalence of sarcopenia in elderly residents in nursing homes in China. Med Sci Monit. 2019;25:4390-9.

43. Beaudart C, Rizzoli R, Bruyère O, Reginster JY, Biver E. Sarcopenia: burden and challenges for public health. Arch Public Health. 2014;72(1):45.

44. Beaudart C, Zaaria M, Pasleau F, Reginster JY, Bruyère O. Health outcomes of sarcopenia: a systematic review and Meta-analysis. Plos One. 2017;12(1):e0169548.

45. Cooper R, Kuh D, Hardy R. Objectively measured physical capability levels and mortality: systematic review and meta-analysis. BMJ. 2010;341:c4467.

46. Yeung SSY, Reijnierse EM, Pham VK, Trappenburg MC, Lim WK, Meskers CGM, et al. Sarcopenia and its association with falls and fractures in older adults: a systematic review and meta-analysis. J Cachexia Sarcopenia Muscle. 2019;10(3):485-500.

47. Cawthon PM, Fox KM, Gandra SR, Delmonico MJ, Chiou CF, Anthony MS, et al. Do muscle mass, muscle density, strength, and physical function similarly influence risk of hospitalization in older adults? J Am Geriatr Soc. 2009;57(8):1411-9.

48. Janssen I, Baumgartner RN, Ross R, Rosenberg $I$, Roubenoff R. Skeletal muscle cutpoints associated with elevated physical disability risk in older men and women. Am J Epidemiol. 2004;159(4):413-21.

49. Reid KF, Naumova EN, Carabello RJ, Phillips EM, Fielding RA. Lower extremity muscle mass predicts functional performance in mobilitylimited elders. J Nutr Health Aging. 2008;12(7):493-8.

50. Rizzoli R, Reginster JY, Arnal JF, Bautmans I, Beaudart C, BischoffFerrari $\mathrm{H}$, et al. Quality of life in sarcopenia and frailty. Calcif Tissue Int. 2013;93(2):101-20.

51. United Nations World Population Prospects, (2019). https://population. un.org/wpp/. Accessed Feb 122022.

52. https://www.ksh.hu/nepszamlalas/tables_regional_00. Accessed Feb 12 2022.

53. Perls TT, Fretts RC. The evolution of menopause and human life span. Ann Hum Biol. 2001;28(3):237-45.

54. Dratva J, Real FG, Schindler C, Ackermann-Liebrich U, Gerbase M, ProbstHensch N, et al. Is age at menopause increasing across Europe? Results on age at menopause and determinants from two population-based studies. Menopause. 2009;16:385-94.

55. Gold EB. The timing of the age at which natural menopause occurs. Obstetr Gynecol Clin North Am. 2011;38:425-40.

56. Aloia JF, McGowan DM, Vaswani AN, Ross P, Cohn SH. Relationship of menopause to skeletal and muscle mass. Am J Clin Nutr. 1991;53(6):1378-83.

57. Rolland YM, Perry HM 3rd, Patrick P, Banks WA, Morley JE. Loss of appendicular muscle mass and loss of muscle strength in young postmenopausal women. J Gerontol A Biol Sci Med Sci. 2007;62(3):330-5.

58. Cevei M, Onofrei RR, Cioara F, Stoicanescu D. Correlations between the quality of life domains and clinical variables in sarcopenic osteoporotic postmenopausal women. J Clin Med. 2020;9(2):441.

59. Cruz-Jentoft AJ, Baeyens JP, Bauer JM, Boirie Y, Cederholm T, Landi F, et al. Sarcopenia: European consensus on definition and diagnosis. Age Ageing. 2010;39:412-23. 
60. Cruz-Jentoft AJ, Bahat G, Bauer J, et al. Sarcopenia: revised European consensus on definition and diagnosis. Age Ageing. 2019;48(1):16-31.

61. World Health Organization. Research on the Menopause in the 1990s: Report of a WHO Scientific Group. Geneva: World Health Organization; 1996. p. 12-4. WHO Technical Report Series No. 866

62. Malmstrom TK, Miller DK, Simonsick EM, Ferrucci L, Morley JE. SARC-F: a symptom score to predict persons with sarcopenia at risk for poor functional outcomes. J Cachexia Sarcopenia Muscle. 2016;7(1):28-36.

63. Roberts HC, Denison HJ, Martin HJ, Patel HP, Syddall H, Cooper C, et al A review of the measurement of grip strength in clinical and epidemiological studies: towards a standardised approach. Age Ageing. 2011;40(4):423-9.

64. Baumgartner RN, Koehler KM, Gallagher D, Romero L, Heymsfield SB, Ross RR, et al. Epidemiology of sarcopenia among the elderly in New Mexico. Am J Epidemiol. 1998;147(8):755-63.

65. Rydwik E, Bergland A, Forsén L, Frändin K. Investigation into the reliability and validity of the measurement of elderly people's clinical walking speed: a systematic review. Physiother Theory Pract. 2012;28(3):238-56.

66. Maggio M, Ceda GP, Ticinesi A, De Vita F, Gelmini G, Costantino C, et al. Instrumental and non-instrumental evaluation of 4-meter walking speed in older individuals. PLoS One. 2016;11(4):e0153583.

67. Cawthon PM, Peters KW, Shardell MD, McLean RR, Dam TT, Kenny AM, et al. Cutpoints for low appendicular lean mass that identify older adults with clinically significant weakness. J Gerontol A Biol Sci Med Sci. 2014;69(5):567-75.

68. Fielding R, Vellas B, Evans W, Bhasin S, Morley J, Newman A, et al. Sarcopenia: an undiagnosed condition in older adults. Current consensus definition: prevalence, etiology, and consequences. International working group on sarcopenia. J Am Med Dir Assoc. 2011;12:249-56.

69. Chen LK, Liu LK, Woo J, Assantachai P, Auyeung TW, Bahyah KS, et al. Sarcopenia in Asia: consensus report of the Asian working group for Sarcopenia. J Am Med Dir Assoc. 2014;15(2):95-101.

70. Hahn RA, Eaker E, Rolka H. Reliability of reported age at menopause. Am J Epidemiol. 1997;146(9):771-5.

71. Hall JE. Neuroendocrine physiology of the early and late menopause. Endocrinol Metab Clin N Am. 2004;33(4):637-59.

72. Kasiulevicius V, Sapoka V, Filipaviciute R. Sample size calculation in epidemiological studies. Gerontology. 2006;7:225-31.

73. Lee WJ, Liu LK, Peng LN, Lin MH, Chen LK. Comparisons of sarcopenia defined by IWGS and EWGSOP criteria among older people: results from the I-Lan longitudinal aging study. J Am Med Dir Assoc. 2013;14:528.e1-7.

74. Bastiaanse LP, Hilgenkamp TI, Echteld MA, Evenhuis HM. Prevalence and associated factors of sarcopenia in older adults with intellectual disabilities. Res Dev Disabil. 2012;33:2004-12.

75. Patel HP, Syddall HE, Jameson K, et al. Prevalence of sarcopenia in community-dwelling older people in the UK using the European working group on sarcopenia in older people (EWGSOP) definition: findings from the Hertfordshire cohort study (HCS). Age Ageing. 2013;42:378-84.

76. Maltais ML, Desroches J, Dionne IJ. Changes in muscle mass and strength after menopause. J Musculoskelet Neuronal Interact. 2009;9(4):186-97.

\section{Publisher's Note}

Springer Nature remains neutral with regard to jurisdictional claims in published maps and institutional affiliations.

Ready to submit your research? Choose BMC and benefit from:

- fast, convenient online submission

- thorough peer review by experienced researchers in your field

- rapid publication on acceptance

- support for research data, including large and complex data types

- gold Open Access which fosters wider collaboration and increased citations

- maximum visibility for your research: over $100 \mathrm{M}$ website views per year

At BMC, research is always in progress.

Learn more biomedcentral.com/submissions 